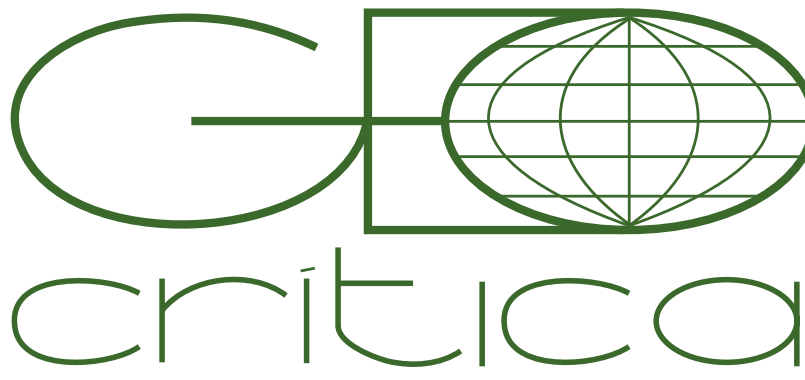

Scripta Nova

Revista Electrónica de Geografía y Ciencias Sociales Universitat de Barcelona

1 de noviembre de 2017

\title{
INFLUENCIA DEL TURISMO RESIDENCIAL SOBRE EL RIESGO DE INUNDACIÓN EN EL LITORAL DE LA REGIÓN DE MURCIA
}

\author{
Francisco López Martínez \\ flm5@um.es \\ Alfredo Pérez Morales \\ alfredop@um.es \\ Universidad de Murcia
}

Recibido: 21 de marzo de 2017. Devuelto para correcciones: 2 de junio de 2017. Aceptado: 30 de julio de 2017.

\section{Influencia del turismo residencial sobre el riesgo de inundación en el litoral de la Región de Murcia (Resumen)}

En las últimas décadas, el litoral mediterráneo español ha experimentado una intensa demanda turístico-residencial que transformaron por completo la dinámica socio-territorial tanto de los municipios de primera línea de costa, como los de áreas limítrofes. Entre los distintos patrones constructivos que rompieron dicha dinámica territorial, el modelo resort destaca debido a elevada representatividad y su rápida integración dentro de los instrumentos de planeamiento urbano local. Al igual que el resto de desarrollos urbanísticos, esta forma de expansión urbana se ha hecho de forma escasamente adaptada a los condicionantes ambientales, principalmente, en lo que se refiere al respeto de las zonas tradicionalmente inundables. Por consiguiente, el presente trabajo pretende evaluar el nivel de permisividad adquirido por los planificadores locales ante el riesgo de inundación, así como la influencia de este modelo constructivo sobre el número de inundaciones. Para ello se han combinado en un SIG las figuras de planeamiento local con la cartografía de zonas inundables.

Palabras clave: resort, riesgo, inundaciones, planificación territorial

\section{Residential tourism influence on flood hazard in the coastline of the Region of Murcia (Abstract)}

In recent years, the Mediterranean coastal area have had an intense tourist-residential demand which absolutely changed the socio-territorial dynamic both coastal municipalities and adjacent locations. Among all the different construction models which broke this territorial dynamic, the resort urban model stands out for its representativeness and because it was quickly integrated into the local urban planning instruments. However, resorts, as the most of the recent urban developments, were built without any rational approach to environmental characteristics, mainly, those related to the surrounding area of several torrential water courses, the flood-prone areas. In this way, this work tries to evaluate the permissiveness level acquired by local planners, and also how resorts has influenced on the increasing number of floods. For this, the spatial planning cartography and flood hazard maps were combined into a GIS.

Key words: resort, hazard, floods, spatial planning 
Durante las tres últimas décadas, el litoral mediterráneo español ha sufrido una intensa transformación urbanística derivada del desarrollo inmobiliario de corte neoliberal ${ }^{1}$. Este voraz proceso urbanizador, favorecido tanto por la disponibilidad de efectivo para los compradores, como por las facilidades de crédito concedidas a los promotores urbanísticos ${ }^{2}$, convirtió el litoral mediterráneo en el motor de crecimiento inmobiliario de España junto con las áreas metropolitanas ${ }^{3}$. Este proceso urbanístico, además de elevar los niveles de consumo territorial a un ritmo muy superior al ocurrido en cualquier otro período histórico ${ }^{4}$, provocó una rápida transformación ambiental ${ }^{5}$, sociodemográfica y territorial que ha modificado por completo la dinámica poblacional, el paisaje y la urbanización tradicional mediterránea tan característica de estas áreas ${ }^{6}$. Como resultado, la proliferación descontrolada de numerosos desarrollos urbanísticos ha provocado un profundo cambio en los usos del suelo, dando lugar a la aparición de edificaciones de muy distinta tipología: bloques de hoteles, apartamentos, colonias, grandes urbanizaciones, etc..., diseñadas para satisfacer desde las necesidades turísticas más exuberantes, hasta las de alojamiento de los trabajadores vinculados a éstos ${ }^{7}$. Sin embargo, dicho crecimiento ha sobrepasado por completo las demandas constructivas de la población residente, la turística y de la inmigración laboral ${ }^{8}$.

Este turismo residencial, cuya actividad central no radica en atraer turistas y ofertarles servicios ${ }^{9}$, está enfocado a un colectivo que, atraído por la elevada oferta inmobiliaria, sus benévolas condiciones climáticas, disponibilidad de servicios de calidad similar e incluso superior a los de sus países de origen (véase sanidad) y su elevado potencial de consumo ${ }^{10}$, desató todo un sin fin estrategias especulativas en el sector litoral inmobiliario. Básicamente el patrón constructivo se repetía siguiendo la misma fórmula: habilitar suelo urbano y urbanizable por medio de modificaciones de las normas urbanísticas, construir el mayor número viviendas y venderlas al mejor precio e independientemente de su posterior ocupación ${ }^{11}$. En consecuencia, dicho proceso ha dado lugar a la construcción de miles de inmuebles tanto para veraneantes nacionales del centro y norte de la Península Ibérica, como para jubilados de la Unión Europea, quienes se han establecido en la zona de forma permanente o casi permanente ${ }^{12}$.

Según Aledo, en España el fenómeno turístico residencial puede dividirse en cinco etapas claramente diferenciadas y caracterizadas por un producto inmobilia-

1 Díaz, 2004; Romero et al., 2012

2 Fernández y Barrado, 2011

3 González, 2008

4 Fernández, 2007

5 Burriel, 2008; Grenon, 1990

6 Aledo, 2008, Mantecón et al., 2009

7 Mazón, 2006

8 Fernández y Barrado, 2011

9 Aledo, 2008, 2016

10 González, 2008

11 Aledo, 2008

12 Mazón, 2006 
rio diferente que no implica la desaparición de las fórmulas anteriores ${ }^{13}$. La primera fase ( 1975 - 1980) ocupó buena parte de la primera línea de costa y destaca por una pequeña urbanización dispersa junto con bloques de apartamentos de diversa altura. En la segunda etapa ( 1980 - 1991/1994), junto con el modelo anterior, apareció un patrón de enorme éxito parcialmente copiado del urbanismo norteamericano: las macrourbanizaciones con cientos de chalets, bungalows y adosados. En la tercera (1994 - 2002), aún sin haber desaparecido los modelos anteriores, surgió la exitosa fórmula de combinar macrourbanizaciones con infraestructuras recreativas como campos de golf ocasionalmente acompañados de hoteles de 4 o 5 estrellas. En la cuarta (2002 - 2007), aparece el conocido como resort turístico-residencial, conformado por espacios privados e independientes en servicios del territorio sobre el que se desarrollan. Por último, durante la quinta etapa (2007-actualidad), el estallido de la burbuja inmobiliaria y su posterior onda expansiva han asfixiado las tasas constructivas, pero han dado lugar a la aparición de nuevas vulnerabilidades sociales, principalmente de carácter económico debido al desempleo y pérdida de rentas entre las clases medias trabajadoras. Atendiendo a las características constructivas de cada etapa, el producto resort está enfocado a potenciar un turismo residencial de acceso controlado y económicamente selectivo donde predomina el espacio privado sobre el público ${ }^{14}$. Este modelo urbanizador, además de ser una de las tipologías constructivas que ocasionan un mayor consumo del recurso suelo ${ }^{15}$, presenta una serie de elementos característicos: 1) está constituido por asentamientos alejados de la periferia de las ciudades y de primera línea litoral; 2) suelen encontrarse bien comunicados a través de grandes vías de acceso y con núcleos poblaciones cercanos de los que absorbe una tematización constructiva, y 3 ) están conformados por estructuras lo suficientemente importantes como para satisfacer las necesidades primarias de sus habitantes y llevar a cabo una desconexión parcial, pero a su vez siguen dependiendo de un asentamiento mayor del que obtienen la mayoría de los servicios que necesitan ${ }^{16}$.

Aunque los resorts poseen un patrón urbanístico bastante característico, pueden identificarse diferentes modelos constructivos ${ }^{17}$. En la actualidad, la modalidad más difundida pertenece a los denominados como "resorts de destino", complejos residenciales capaces de satisfacer todas las necesidades del visitante (alimentación, alojamiento, ocio, compras, etc...) con un nivel de calidad superior al hotel medio de cualquier ciudad ${ }^{18}$.

Aunque tradicionalmente los resorts han estado fuertemente vinculados con áreas costeras, políticamente se ha intentado justificar su traslado hacia zonas interiores con la intención de distribuir los beneficios derivados del turismo y desma-

13 Aledo, 2016

14 Mena, 2010

15 Fernández, 2007

16 Mena, 2010; Mazón y Aledo, 2005

17 Mena, 2010

18 Mena, 2010 
sificar la primera línea de costa ${ }^{19}$. Sin embargo, la elevada densificación turística a la que se ha visto sometida el litoral, el devastador proceso consumista del recurso suelo y la creciente demanda de nuevos territorios, han sido las verdaderas causas que han comprometido su continuidad ${ }^{20}$. En este sentido, con la intención de garantizar su persistencia debido a sus abundantes beneficios económicos, el modelo resort se ha visto obligado a desplazarse en un primer momento hacia municipios mediterráneos de "segunda línea" y, posteriormente, de interior ${ }^{21}$.

Dicho modelo turístico-residencial del tipo resort fue rápidamente interpretado por la mayoría de municipios mediterráneos, tanto de áreas litorales como de interior, como una fuente de riqueza para resolver problemas económicos que experimentaban las entidades locales ${ }^{22}$. La respuesta de los mismos fue rápida y las diferentes administraciones encargadas de la ordenación territorial se lanzaron a modificar sus figuras de planeamiento local para acomodar los resort en sus ámbitos administrativos ${ }^{23}$. Un ejemplo característico del respaldo e interés de los gobiernos autonómicos por el turismo residencial está reflejado en las Actuaciones de Interés Regional de la ley del Suelo de la Región de Murcia, instrumento de ordenación territorial utilizado de manera excepcional para respaldar los diferentes proyectos turístico-urbanísticos del Campo de Cartagena ${ }^{24}$. A este respecto, la fuerte presión mercantil y la especulación del recurso suelo provocaron cierta laxitud y, en el peor de los casos, la omisión de diversos condicionantes urbanísticos legalmente establecidos ${ }^{25}$, especialmente aquellos relacionados con la gestión preventiva de riesgos de origen natural ${ }^{26}$. Esta situación adquirió especial relevancia en zonas sometidas a una fuerte presión turística, como el sureste peninsular, donde se ha verificado un notorio incremento en el número de inundaciones ${ }^{27}$, así como de edificaciones expuestas $^{28}$.

Aunque las diferentes administraciones públicas poseen como principal cometido limitar la exposición a los peligros de origen natural de sus ciudadanos ${ }^{29}$ para mitigar su impacto ${ }^{30}$, diversas cuestiones políticas $y$, fundamentalmente económicas, han distorsionado su cometido ${ }^{31}$. Es decir, el aumento de la exposición ${ }^{32}$ delata que las administraciones encargadas de la ordenación territorial han perdido su fun-

19 Aledo, 2008

20 Mena, 2010

21 Aledo y Mazón, 1997; Mazón, 2006; Mena, 2010

22 Inskeep, 1991

23 Bellod, 2007; Burriel, 2008

24 Aledo, 2016

25 Ley 6/1998, de 13 de abril, sobre régimen del suelo y valoraciones; Ley 8/2007, de 28 de mayo, de suelo; Real Decreto Legislativo 2/2008, de 20 de junio, por el que se aprueba el texto refundido de la Ley del suelo.

26 Pérez-Morales, 2009

27 Gil-Guirado et al., 2014

28 Pérez-Morales et al., 2015a

29 Giddens, 2002

30 Fuchs, 2009

31 Pérez-Morales et al., 2015a

32 Sutanta et al., 2010 
ción de agente armonizador entre las necesidades de la sociedad y las características del territorio ${ }^{33}$, convirtiéndose en las principales responsables de los denominados como "territorios de riesgo"34. Para contrarrestar esta situación, tradicionalmente la gestión de riesgos de inundación ha sido abordada desde el conocido como "paradigma ingenieril" ${ }^{35}$, es decir, a través de ingentes y costosas medidas estructurales que, lejos de solventar el problema ${ }^{36}$, han generado una falsa sensación de seguridad denominada como "el efecto dique" ${ }^{37}$.

Por otro lado, también hay que considerar que la gestión de riesgos a través de la ordenación territorial presenta una serie de debilidades directamente relacionadas con las presiones externas a las que se encuentra sometida ${ }^{38}$. En este sentido, según Smith y Petley ${ }^{39}$ las principales limitaciones de la ordenación territorial son: falta de conocimiento, existencia de zonas ya desarrolladas, la poca frecuencia de algunos eventos, la dificultad de sensibilizar a la población, los altos costes de la cartografía de riesgos y la resistencia local a los controles normativos. Sin embargo, diversos autores y entidades internaciones ${ }^{40}$ defienden la ordenación del territorio como la primera medida defensiva no estructural más racional, con menor impacto ambiental y coste económico para la reducción de riesgo, especialmente del ocasionado por los fenómenos de inundación. No obstante, pese a los beneficios señalados, la ordenación del territorio también presenta problemas en su aplicación, pues en más ocasiones de las deseadas, ésta se hace de forma incompleta o deficiente ${ }^{41} \mathrm{y}$ sus errores se traducen, en lo que respecta a las inundaciones, en un aumento de la exposición ${ }^{42}$. Se puede llegar a entender que este resultado viene dado por una incorrecta imbricación en el modelo de desarrollo territorial del conjunto de elementos físicos con los humanos, o lo que es lo mismo, los instrumentos de ordenación presentan una serie de defectos o vulnerabilidades ${ }^{43}$ que se traducen en un aumento de la exposición.

El término vulnerabilidad, entendido como "las características de una persona o grupo y su situación, que influencian su capacidad de anticipar, lidiar, resistir y recuperarse del impacto de una amenaza" 44 , está compuesto por diferentes dimensiones ${ }^{45}$. Dentro de las diversas dimensiones o factores que componen el término

33 Según la Constitución Española de 1978 y la Sentencia 61/1997 del Tribunal Constitucional, en España las administraciones públicas competentes en la ordenación territorial y urbanística son las Comunidades Autónomas y los municipios respectivamente. El Estado sólo tiene potestad para redactar normativa básica.

34 Calvo, 2001

35 Smith y Petley, 2009

36 Holub y Fuchs, 2009; Fusch et al., 2017; Pérez-Morales et al., 2015b

37 Lane et al., 2011

38 Neuvel y Van den Brink, 2009; Sutanta et al., 2010

39 Smith y Petley, 2009

40 Olcina, 2004; Directiva 2007/60/CE; IPPC, 2012

41 Smith y Petley, 2009

42 Pérez-Morales et al., 2015a; 2015b; Fusch et al., 2017

43 CRED, 2009; Parker et al., 2009

44 Wisner et al., 2004

45 Calvo, 1997; Fusch, 2009; Wisner et al., 2004 
vulnerabilidad, las carencias en las estrategias de ordenación territorial inciden directamente dentro de la denominada como vulnerabilidad institucional ${ }^{46}$, pues refleja fielmente la permisividad y, en algunos casos negligencia, adquirida por las diferentes administraciones públicas encargadas de promulgar, gestionar y aplicar los condicionantes normativos. Según Wisner ${ }^{47}$, el principal causante de la debilidad institucional es la corrupción, sin embargo, también debe considerarse el tratamiento normativo de los problemas derivados de las inundaciones ${ }^{48}$, pues los gobiernos locales no están dispuestos a aprobar medidas de actuación sino existe una normativa de carácter superior que los obligue ${ }^{49}$.

Teniendo en cuenta todo lo anterior, en el presente trabajo se analiza la influencia del fenómeno turístico, concretamente del modelo resort, sobre el planeamiento urbanístico local del municipio de Torre Pacheco (Región de Murcia, España) a efectos de: 1) identificar cómo el planeamiento local ha imbricado el desarrollo turístico del modelo resort con las zonas inundables y 2) evaluar si la transformación urbanística introducida por los resorts ha incrementado la vulnerabilidad institucional.

\section{Área de estudio}

Torre Pacheco es un municipio de $189 \mathrm{~km}^{2}$ localizado en la zona E de la Región de Murcia (SE de España), en la denominada como Comarca Oriental ${ }^{50}$. Aunque estrictamente se considera como un municipio de interior, su distancia con el Mar Menor es inferior a $5 \mathrm{~km}$. (Figura 1). Desde un punto de vista poblacional es el octavo municipio más poblado de la Región, pues en su territorio residen 34.469 habitantes (INE, 2015) distribuidos a lo largo del término municipal en once núcleos urbanos. Los de mayor entidad son Torre Pacheco (donde habita un 52\% de la población), Roldán (19\%) y Balsicas (9\%) y, los menos poblados Santa Rosalía (0,41\%), Los Camachos $(0,53 \%)$ y Los Meroños ( $1,22 \%)$. Según el último censo oficial de población y vivienda realizado por el INE (2015), durante la última década el municipio ha sufrido un notorio incremento de población extranjera desde un 15,30 \% en 2001 hasta un $29,21 \%$ en 2011 (porcentaje que se traduce en 2.313 personas). Aunque la mayoría de población extranjera se dedica a labores agrícolas de regadío ${ }^{51}$, actualmente más de un $5 \%$ de los habitantes censados corresponden a turistas de alto poder adquisitivo originarios de diversos países europeos, especialmente de Reino Unido. Esta población se ubica en su mayoría en tres resort de gran porte urbanístico y superficial que sobrepasan sus necesidades habitacionales hasta el extremo que ninguno de ellos alcanza su ocupación máxima. Todo lo anterior refuerza la influencia del ya comentado proceso especulativo, que sitúo al municipio de Torre Pacheco como

46 Wilches-Chaux, 1993; Parker et al., 2009

47 Wisner, 2000

48 ARMONIA, 2005

49 Burby y Dalton, 1994

50 Fuentes y Calvo, 1984

51 CREM, 2015 
el tercer municipio de España de más de 20.000 habitantes, con mayor crecimiento relativo en número de viviendas entre 2001 y 2011 ( 1 15,5\%) y el primero en porcentaje de viviendas vacías $(35,9 \%)^{52}$.

Según Mena ${ }^{53}$, dentro del término municipal de Torre Pacheco los resorts existentes, en desarrollo o planificados pueden clasificarse en dos grandes grupos: industriales y deportivos. Los primeros están respaldados por un conjunto de empresas instaladas en un espacio agrícola capaces de ofrecer un producto urbanístico y de ocio completamente terminado al que, generalmente, incluyen su mantenimiento futuro. Esta modalidad de resort están dirigidos a un grupo turístico de alto poder adquisitivo, por lo que suelen ofrecer servicios más exclusivos y de mayor calidad. Por otro lado, los deportivos, además de ofertar un producto final conformado por equipamientos deportivos y campos de golf, conceden la libertad de diseñar y construir diversas tipologías de instalaciones urbanas a su alrededor (locales comerciales, equipamientos, servicios, etc...) a empresas diferentes a la promotora del complejo principal. El resultado final es el de un complejo más abierto y con ca-

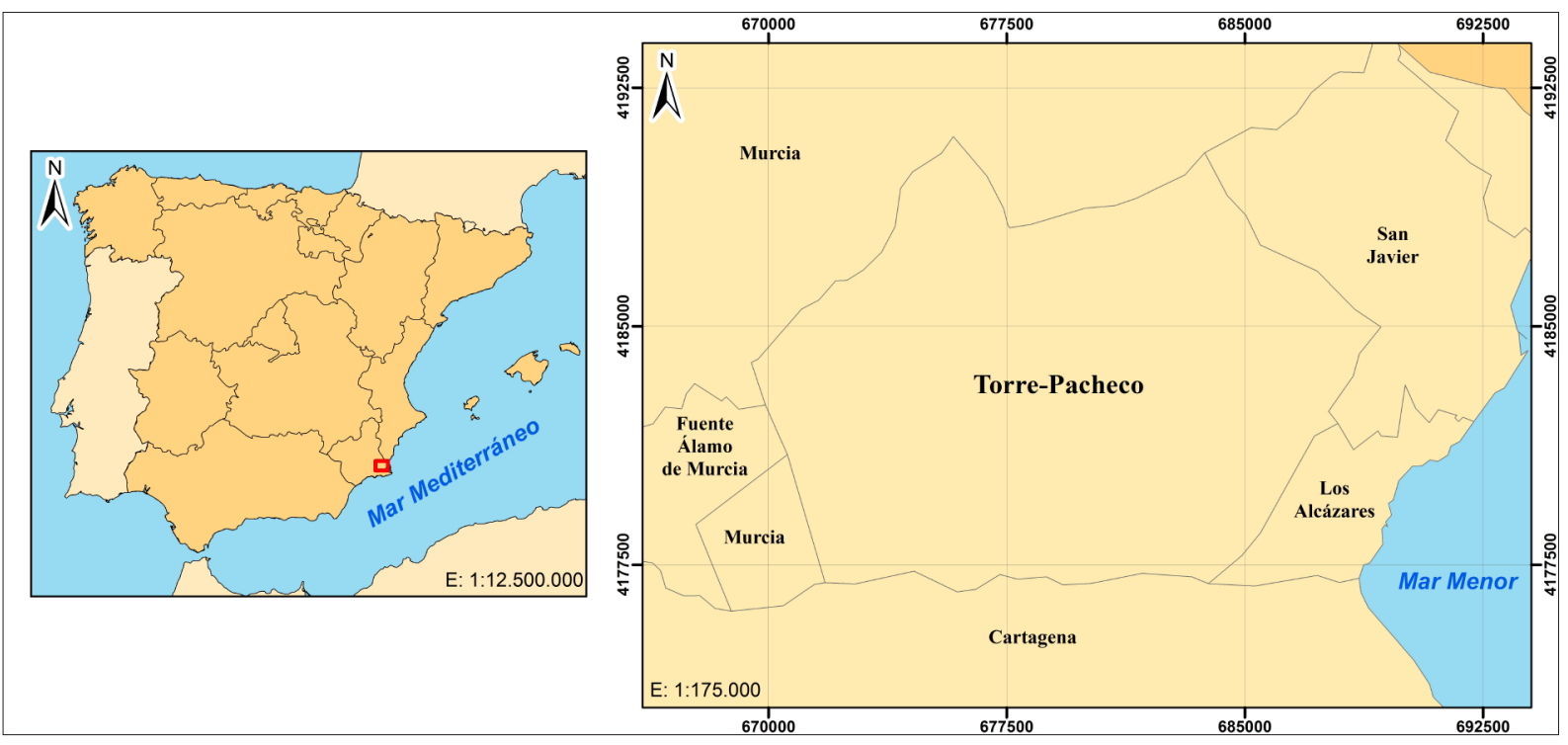

Figura 1: Localización del área de estudio.

Fuente: Elaboración propia.

racterísticas constructivas más heterogéneas.

En relación con las vías de comunicación, una de las grandes infraestructuras que condicionan su ubicación ${ }^{54}$, los resort están ubicados en el área de influencia de los dos núcleos poblacionales más importantes de la Región de Murcia: Murcia y Cartagena. Entre ambas localidades se desarrolla una amplia infraestructura comunicativa, especialmente viaria, donde destacan las carreteras provinciales RM-19, RM-F30 y la autovía A-30, principales rutas de acceso a los municipios más turísticos del litoral murciano (Cartagena, Los Alcázares, San Javier y San Pedro del Pinatar).

52 Romero et al., 2017

53 Mena, 2010

54 Mena, 2010 
En relación a los elementos físicos que condicionan la ocupación del área de estudio, debe enfatizarse la presencia de una serie de factores que caracterizan las inundaciones de la Cuenca Mediterránea. En primer lugar cabe destacar la componente climática ${ }^{55}$. Este factor es el principal responsable de la desigual intensidad y distribución pluviométrica que caracteriza la zona y cuyos máximos, registrados en los meses de otoñ $0^{56}$, son los causantes de los graves fenómenos de inundación ${ }^{57}$. En último lugar, aunque el área de estudio carece de un gran curso hidrológico, presenta multitud de pequeños cursos fluviales de comportamiento torrencial cuya fuerte transformación antrópica ha modificado por completo su dinámica natural ${ }^{58}$.

\section{Metodología y fuentes}

Para identificar tanto la relación de los resort con las zonas inundables, como su influencia sobre la vulnerabilidad institucional, se analizará la situación actual y futura, así como la evolución, de las dos fuentes cartográficas encargadas de definir la exposición ${ }^{59}$ : las figuras de planeamiento local y la superficie de las zonas inundables.

\section{Planificación territorial y desarrollo de los complejos resort}

A pesar de que los distintos núcleos poblacionales del término municipal de Torre Pacheco rigen desde el año 1987 su planeamiento urbanístico a través de Normas Subsidiarias de Planeamiento General (NNSS), no sería hasta 1995 cuando se produciría su aprobación definitiva ${ }^{60}$. Dichas NNSS fueron redactadas bajo el amparo legislativo de los ya derogados Real Decreto $1346 / 1976^{61}$ y su posterior desarrollo normativo, Real Decreto 2159/197862. Según establecen ambas normativas, ante la ausencia de una figura de carácter superior, el Plan General Municipal de Ordenación Urbana (PGMOU), las NNSS son el instrumento urbanístico del que disponen los municipios de tamaño mediano para regular su planeamiento. Debido a su antigüedad, tanto las citadas normativas de carácter estatal como las NNSS de la localidad, no contemplan en ningún momento la presencia de riesgos de origen natural, o de cualquier otro tipo, como un factor condicionante o limitante para el desarrollo del planeamiento urbanístico.

Aunque las NNSS han continuado vigentes tras la aprobación de diversas normativas estatales y autonómicas en materia de ordenación territorial, éstas han sido modificadas y adaptadas tanto a sus condicionantes legales, como a las necesidades

55 Por ejemplo, Llasat et al., 2010; Romero y Maurandi, 2000

56 Barredo, 2007; Llasat et al., 2010

57 Por ejemplo, Camarasa-Belmonte, 2002; Camarasa-Belmonte y Soriano-García, 2012

58 Hooke, 2006

59 Cardona et al., 2012

60 Orden del Excmo. Sr. Consejero de Política Territorial y Obras Públicas de 30 de junio de 1995.

61 Real Decreto 1346/1976, de 9 de abril, por la que se aprueba el texto refundido de la Ley sobre Régimen del Suelo y Ordenación Urbana.

62 Real Decreto 2159/1978, de 23 de junio, por el que se aprueba el Reglamento de Planeamiento para el desarrollo y aplicación de la Ley sobre Régimen del Suelo y Ordenación Urbana. 
urbanísticas del municipio para dar cabida a los resorts. Según la aprobación inicial del nuevo Plan General Municipal de Ordenación (PGMO) de 2005, se reservan 920 ha. (aproximadamente el 5\% de la superficie municipal) para el desarrollo de instalaciones turísticas y de ocio (donde se incluyen los resort). Sin embargo, como dicho PGMO todavía no ha sido aprobado definitivamente pues su tramitación ha sido paralizada sine die, las NNSS siguen estando vigentes aunque representan una figura administrativamente desfasada, pues la actual legislación autonómica en materia de ordenación territorial63 obliga a todos los municipios a disponer como único instrumento de desarrollo urbanístico de un PGMO.

La actual cartografía digital de las NNSS ha sido facilitada en formato perfectamente compatible con un SIG por el Sistema de Información Territorial de la Región de Murcia64. SITMURCIA es un geoportal desarrollado por la Unidad de Información Territorial, organismo dependiente de la Consejería de Fomento, Obras Públicas y Ordenación del Territorio, que se encarga de proporcionar la infraestructura de datos espaciales según los requisitos establecidos por la Directiva INSPIRE65. Con la intención de simplificar su posterior análisis, las habituales denominaciones de usos de suelo recogidas en la cartografía digital de las NNSS fueron agrupadas según su carácter constructivo en tres grandes categorías: 1) Urbano, comprende zonas que ya hans sido transformadas por el planeamiento, 2) Urbanizable, representa áreas aptas para su urbanización en un momento temporal cercano aunque indeterminado y, 3) No Urbanizable, abarca el suelo reservado del proceso constructivo debido a alguna característica especial (protección específica, protegido o inadecuado) (cuadro 1). En este último apartado ha sido incluido el suelo definido como "Sistema general", correspondiente a aquellas zonas reservadas al desarrollo de infraestructuras de interés público (carreteras, equipamientos, centro eléctricos, etc...).

\begin{tabular}{lccc}
\hline Tipo de suelo & Categoría & Área (ha) & $\%$ \\
\hline Sistema general & & & \\
No urbanizable protegido & No urbanizable & $16.996,63$ & 89,66 \\
No urbanizable inadecuado & & & \\
\hline Urbano & Urbano & 676,01 & 3,57 \\
\hline Apto para urbanizar & Urbanizable & $1.284,28$ & 6,77 \\
\hline
\end{tabular}

Cuadro 1: Distintos tipos de suelo incluidos en las NNSS y su reclasificación. Fuente: Elaboración propia.

63 Ley 13/2015, de 30 de marzo, de ordenación territorial y urbanística de la Región de Murcia. 64 SITMURCIA, 2015

65 Directiva 2007/2/CE del Parlamento Europeo y del Consejo de 14 de marzo de 2007 por la que se establece una infraestructura de información espacial en la Comunidad Europea (Inspire). 
Una vez definidas las diferentes categorías de suelo, el siguiente paso consistió en identificar las áreas donde los resorts ya han sido construidos o donde el suelo, aun siendo apto para su construcción (categoría de urbanizable), todavía no han llegado a materializarse. Para llevar a cabo este cometido se utilizaron los datos proporcionados por la Dirección General del Catastro (MHAP, 2014), ortofotografías de máxima actualidad y visita de campo. Tras realizar este filtrado se establecieron dos grupos: el primero lo constituyen aquellos resorts que ya han sido edificados de modo total o parcial y donde se enmarcan los complejos denominados como "Mar Menor I y II", "La Torre Golf" y "Saurines La Torre Golf Resort". El segundo está conformado por los resorts planificados pero no construidos, en este caso aparece únicamente el complejo denominado "Las Terrazas" (figura 2). Según la dinámica de la zona estudiada por Mena (2010), en poco tiempo los residenciales más cercanos a la localidad de Torre Pacheco formaran parte del entramado urbano.

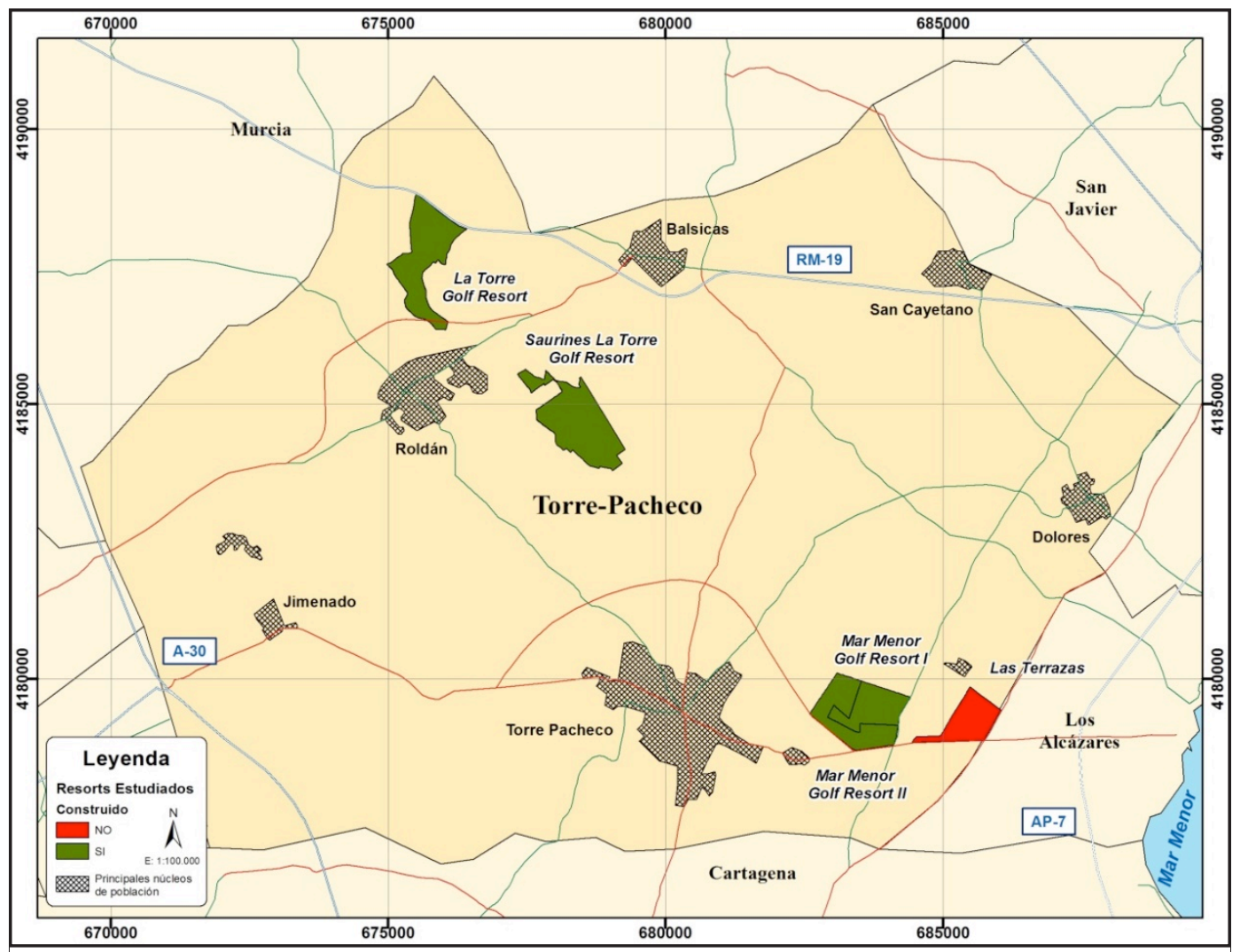

Figura 2: Localización de los resort construidos y planificados en el término municipal de Torre Pacheco. En la figura pueden apreciarse dos características básicas de estos complejos: su cercanía a núcleos urbanos de mayor entidad y su fácil accesibilidad a grandes viales de comunicación.

Fuente: Elaboración propia.

\section{Mapas de zonas inundables, de una cartografía nacional a una europea}

A lo largo de las últimas décadas, diversas normativas sectoriales han abordado la problemática derivada de un fenómeto natural tan recurrente como las inundaciones $^{66}$, sin embargo, habrá que esperar hasta el año 1995 para encontrar el primer

66 Olcina, 2010 
texto legal encargado de tratar directamente sus riesgos derivados: la Directriz Básica ante el Riesgo de Inundaciones ${ }^{67}$ (DBRI o Directriz). Entre otros condicionantes, la DBRI establecía la obligatoriedad de desarrollar en todas las Comunidades Autónomas un plan sectorial capaz de integrar la variable inundabilidad dentro de la ordenación territorial. Para alcanzar esta premisa, el principal cometido de la Directriz consistía en determinar territorialmente el riesgo de inundación a través de una serie de estudios hidrológicos e hidráulicos, cuyos resultados serían posteriormente representados en una cartografía de zonas de riesgo. Según su apartado 2.2.1, dichas zonas de riesgo debían ser clasificadas, en función del período de retorno considerado ( $\mathrm{T}$, expresado en años), como áreas de inundación frecuente $(\mathrm{T}<50)$, ocasional $(50<\mathrm{T}<100)$ y excepcional ( $100<\mathrm{T}<500$ ). Además de esta clasificación, dentro de cada área se establecieron una serie de subzonas (A-1, A-2, A-3, B y C) en función de los efectos sobre las poblaciones.

Al contrario que ocurrió en otras comunidades autónomas como el País Vasco (1999), la Comunidad Valenciana (1999) o Navarra (2002), donde se adoptaron con anterioridad los preceptos de la DBRI, en la Región de Murcia no se publica hasta el 2007 la primera cartografía de zonas inundables en el Plan INUNMUR (Plan Especial de Protección Civil ante el riesgo de inundaciones de la Comunidad Autónoma de la Región de Murcia). A pesar de las diversas limitaciones del Plan INUNMUR68, éste debía ser considerado como la cartografía oficial de consulta por los órganos competentes durante el proceso de planificación territorial y definición de los usos del suelo, siempre y cuando el organismo de cuenca competente no dicte lo contrario o disponga de una delimitación sustitutoria69. Desafortunadamente, aunque la consideración de dicha cartografia sectorial estaba estipulada en el artículo 9.1 de la Ley del Suelo de 1998, no siempre ha sido considerada durante el proceso de ordenación territorial, especialmente en el ámbito territorial de la Región de Murcia, tal y como han demostrado trabajos anteriores70.

Posteriormente, desde la promulgación de la Directiva ante inundaciones (Directiva 2007/60/CE), todos los países europeos tenían la obligación de desarrollar mapas de inundaciones que debían ser integrados dentro de la ordenación territori$a^{71}$. En España la Directiva fue traspuesta al ordenamiento jurídico interno del país a través del Real Decreto 903/201072. Esta normativa derogó los anteriores mapas de zonas inundables establecidos por la DBRI e instauró, en aquellas áreas donde fueran desarrollados, al Sistema Nacional de Cartografía de Zonas Inundables (SNCZI) como la cartografía oficial de consulta ante el peligro de inundaciones ${ }^{73}$. El SNCZI

67 Resolución de 31 de enero de 1995, de la Secretaría de Interior, por la que se dispone la publicación del Acuerdo del Consejo de Ministros por el que se aprueba la Directriz Básica de Planificación de Protección Civil ante el Riesgo de Inundaciones.

68 Pérez-Morales, 2009

69 Pérez-Morales, 2012

70 Pérez-Morales et al., 2015a

71 Moel et al., 2009; Directiva 2007/60/EC

72 Real Decreto 903/2010, de 9 de julio, de evaluación y gestión de riesgos de inundación.

73 Olcina et al., 2010; Pérez-Morales, 2012 
representa un instrumento de ámbito nacional desarrollado para apoyar la gestión de espacio fluvial, la prevención de riesgos, la planificación territorial y la transparencia administrativa ${ }^{74}$. Aunque desde su primera publicación el SNCZI posee un visor de libre acceso ${ }^{75}$ donde se pueden consultar las zonas afectadas, la Dirección General del Agua del Ministerio de Agricultura, Alimentación y Medio Ambiente ${ }^{76}$ ha proporcionado la base cartográfica del SNCZI en formato perfectamente compatible con un SIG. Esta cartografía ha servido para establecer la delimitación de las zonas inundables para los períodos de retorno de 10 (T10), 50 (T50), 100 (T100) y 500 (T500) años que corresponden, respectivamente, con áreas de alta, frecuente, media u ocasional y baja o excepcional probabilidad.

A pesar de que la cartografía sobre zonas inundables recogida tanto en el Plan INUNMUR como en el SNCZI coincide en tres períodos de retorno (T50, T100 y T500), la superficie incluida en cada uno es completamente diferente (cuadro 2). En esencia, esta discrepancia de resultados está motivada tanto por los distintos datos de partida utilizados por cada uno (modelo digital del terreno, registros pluviométricos, modificaciones antrópicas del terreno, etc...), así como por los avances tecnológicos de las herramientas utilizadas (hardware y software) para realizar las modelizaciones hidrológicas e hidráulicas. Por otro lado y según datos del MAGRAMA77, actualmente el SNCZI no actualmente la cobertura espacial del SNCZI no abarca la totalidad de la red hidrográfica española (de media el 29,68 \% de los cauces principales), por lo que aún existen un número indeterminado de cursos fluviales de entidad espacial media y pequeña que, aunque aparentemente no presentan rasgos de peligrosidad, deben ser considerados cuando su trazado intersecciona con áreas urbanas.

\begin{tabular}{lcccc}
\hline & \multicolumn{2}{c}{ Plan INUNMUR } & \multicolumn{2}{c}{ SNCZI } \\
\cline { 2 - 5 } $\mathbf{T}$ & $\begin{array}{c}\text { Región de } \\
\text { Murcia }\end{array}$ & Torre Pacheco & $\begin{array}{c}\text { Región de } \\
\text { Murcia }\end{array}$ & Torre Pacheco \\
\hline $\mathbf{1 0}$ & --- & --- & $17.171,08$ & $2.181,71$ \\
$\mathbf{5 0}$ & $12.717,6$ & 369,15 & $31.198,1$ & $3.530,22$ \\
$\mathbf{1 0 0}$ & $15.739,1$ & 416,51 & $42.246,62$ & $4.033,65$ \\
$\mathbf{5 0 0}$ & $20.941,28$ & 483,68 & $58.430,9$ & $4.913,48$ \\
\hline
\end{tabular}

Cuadro 2: Comparativa de la superficie inundable a nivel regional y local según cada cartografía (datos expresados en hectáreas). Fuente: Elaboración propia a partir de los datos del Plan INUNMUR y SNCZI.

74 MAGRAMA, 2015

75 http://sig.magrama.es/snczi/visor.html?herramienta=DPHZI

76 MAGRAMA, 2013

77 MAGRAMA, 2016 
En último lugar cabe destacar que tanto la vigente normativa en materia de ordenación territorial a nivel autonómico (Ley 13/2015), como estatal ${ }^{78}$, han mantenido en su articulado la obligatoriedad establecida en la Ley 6/1998 de incorporar y considerar los mapas de riesgos de origen natural durante el proceso de transformación urbanística del suelo. Como resultado final, ambos textos disponen que las zonas susceptibles de presentar algún riesgo de origen natural deben ser preservadas del proceso urbanizador, bien sea mediante su clasificación como suelo no urbanizable de protección específica (normativa regional) o su inclusión dentro de la situación básica de suelo rural (normativa estatal).

\section{La vulnerabilidad institucional. Consecuencia turística o dinámica local}

A partir de las tres fuentes cartográficas anteriores, el siguiente paso consiste en cuantificar y analizar el estado y evolución de la vulnerabilidad institucional. Para ello se intersectarán a través de un SIG las diferentes categorías de suelo recogidas en las NNSS tras su agrupación con las distintas cartografías de áreas inundables (Plan INUNMUR y SNCZI).

Aunque la cartografía digital de las NNSS no refleja la fecha de aprobación de sus distintas modificaciones sectoriales, en función de las actuales categorías de suelo se han establecido dos momentos temporales diferentes. Estos periodos numéricamente representados como superficie urbana inundable (SUBI) y superficie urbanizable inundable (SUZI) representan, respectivamente, el porcentaje de suelo urbano y urbanizable en zona inundable respecto al total de suelo municipal que posee la misma categoría.

En este sentido, ante la carencia de modelizaciones futuras tanto hidrológicas como de consumo de suelo, ambos aspectos han sido considerados como estables a lo largo del tiempo ${ }^{79}$, sin embargo se asume que están influenciados por diversas dinámicas socioterritoriales que les harán cambiar a lo largo del tiempo. Por otro lado, aunque anteriormente se comentó que ya existen ciertos resort edificados total o parcialmente, para valorar su influencia sobre el planeamiento local todos han sido considerados en fase de planificación, es decir, como suelo "urbanizable".

$$
\begin{gathered}
\text { SUBI }=\frac{\text { Suelo urbano inundable }}{\text { Suelo urbano municipal }} \times 100 \\
\text { SUZI }=\frac{\text { Suelo urbanizable inundable }}{\text { Suelo urbanizable municipal }} \times 100
\end{gathered}
$$

Finalmente, para valorar la influencia de los resort (IR) sobre la SUZI se cuantificará la relación existente entre la superficie inundable de los resorts respecto al resto de suelo urbanizable inundable municipal.

78 Real Decreto Legislativo 7/2015, de 30 de octubre, por el que se aprueba el texto refundido de la Ley de Suelo y Rehabilitación Urbana.

79 Por ejemplo, Jongman et al., 2014; Pérez-Morales et al., 2015a 


$$
\mathrm{R}=\frac{\frac{\text { Superficie urbanizable inundable resorts }}{\text { Superficie urbanizable resorts }}}{\frac{\text { Superficie urbanizable inundable municipal sin resorts }}{\text { Suberficie urbanizable municival sin resorts }}}
$$

De esta forma se entiende que, cuanto más próxima a la unidad sea la IR, mayor será la contribución que hacen los resort en el aumento de la exposición al peligro de inundación a nivel municipal.

\section{Resultados}

Una vez realizadas las pertinentes intersecciones entre la capa de planeamiento y las distintas capas relativas a la cartografía de zonas inundables, los resultados obtenidos han sido los siguientes:

\section{NNSS y Plan INUNMUR}

Debido a que la redacción y posterior aprobación de las NNSS fue bastante anterior a la publicación del Plan INUNMUR, las diferentes zonas inundables (cuadro 2) y afecciones parciales (trece puntos críticos en vías de comunicación y algunas viviendas aisladas pertenecientes al núcleo urbano del Albujón) registradas en dicho instrumento de planificación sectorial en el término municipal de Torre Pacheco, no han sido consideradas en las NNSS. Sin embargo, a pesar de la omisión de dicha cartografía por sus diferencias temporales, la dinámica socioterritorial de los diversos núcleos urbanos del término municipal de Torre Pacheco ha adaptado perfectamente sus estadios de crecimiento con los fenómenos de inundación, pues la SUBI es de media inferior al $1 \%$ (cuadro 3). Por el contrario, atendido a las futuras perspectivas de crecimiento y, suponiendo, que el Plan INUNMUR representase la cartografía de zonas inundables vigente, de media la SUZI $(0,79 \%)$ supera para los distintos T en aproximadamente un $36 \%$ a la SUBI $(0,58 \%)$.

\begin{tabular}{lccccc}
\hline T & $\begin{array}{c}\text { Superficie } \\
\text { inundable } \\
\text { (ha) }\end{array}$ & $\begin{array}{c}\text { Superficie } \\
\text { urbana } \\
\text { inundable } \\
\text { (ha) }\end{array}$ & SUBI & $\begin{array}{c}\text { Superficie } \\
\text { urbanizable } \\
\text { inundable } \\
\text { (ha) }\end{array}$ & SUZI \\
\hline $\mathbf{5 0}$ & 369,15 & 3,26 & 0,48 & 7,03 & 0,55 \\
$\mathbf{1 0 0}$ & 416,51 & 3,76 & 0,56 & 9,03 & 0,70 \\
$\mathbf{5 0 0}$ & 483,68 & 4,64 & 0,69 & 14,51 & 1,13 \\
\hline Promedio & 423,11 & 3,89 & 0,58 & 10,19 & 0,79 \\
\hline
\end{tabular}

Cuadro 3: Superficie y porcentaje de las zonas inundables según el T. Fuente: Elaboración propia. 
Por su parte, diferenciando los resort del planeamiento municipal, según dicha cartografía e independientemente del T considerado, las inundaciones sólo afectarían a dos complejos residenciales: “Las Terrazas" y “Mar Menor Golf Resort II" (cuadro 4). Sin embargo, mientras que el primero se vería afectado en distintas intensidad por todos los T (cabe destacar que presenta casi un $10 \%$ de superficie inundable ante los eventos más recurrentes (T50) menos de un $2 \%$ del segundo lo haría por las inundaciones más inusuales (T500).

\begin{tabular}{lcccr}
\hline Resort & T & $\begin{array}{c}\text { Superficie } \\
\text { inundable (ha) }\end{array}$ & $\begin{array}{c}\text { Superficie } \\
\text { resort (ha) }\end{array}$ & \% inundable \\
\hline Las Terrazas & 50 & 6,56 & 68,36 & 9,60 \\
Las Terrazas & 100 & 8,36 & 68,36 & 12,24 \\
Mar Menor Golf Resort II & 500 & 1,13 & 89,23 & 1,26 \\
Las Terrazas & 500 & 11,66 & 68,36 & 17,05 \\
\hline
\end{tabular}

Cuadro 4: Datos básicos de cada resort y porcentaje de superficie en zona inundable.

Fuente: Elaboración propia.

En lo que se refiere al valor de la IR, para cualquier T la superficie inundable registrada en los resorts supera de media 30 veces la superficie inundable afectada a nivel municipal (figura 3).

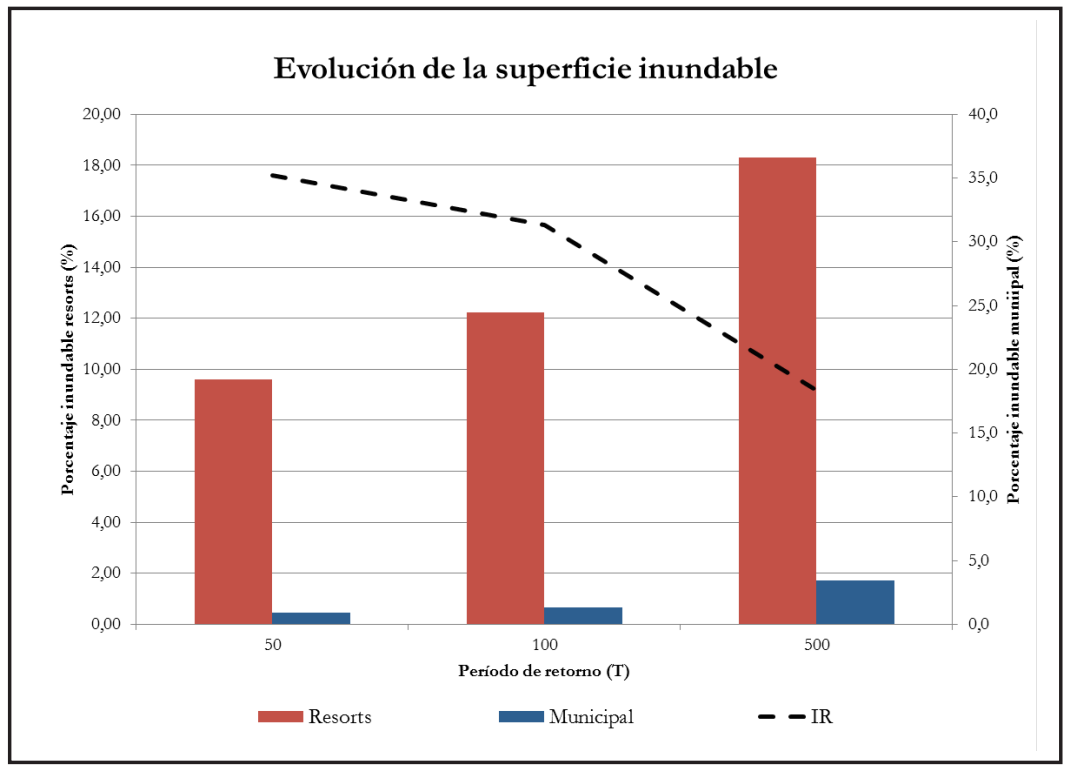

Figura 3: Figura 5: Gráfico con los porcentajes de superficie inundable registrada a nivel municipal y para los resorts. Fuente: Elaboración propia. 


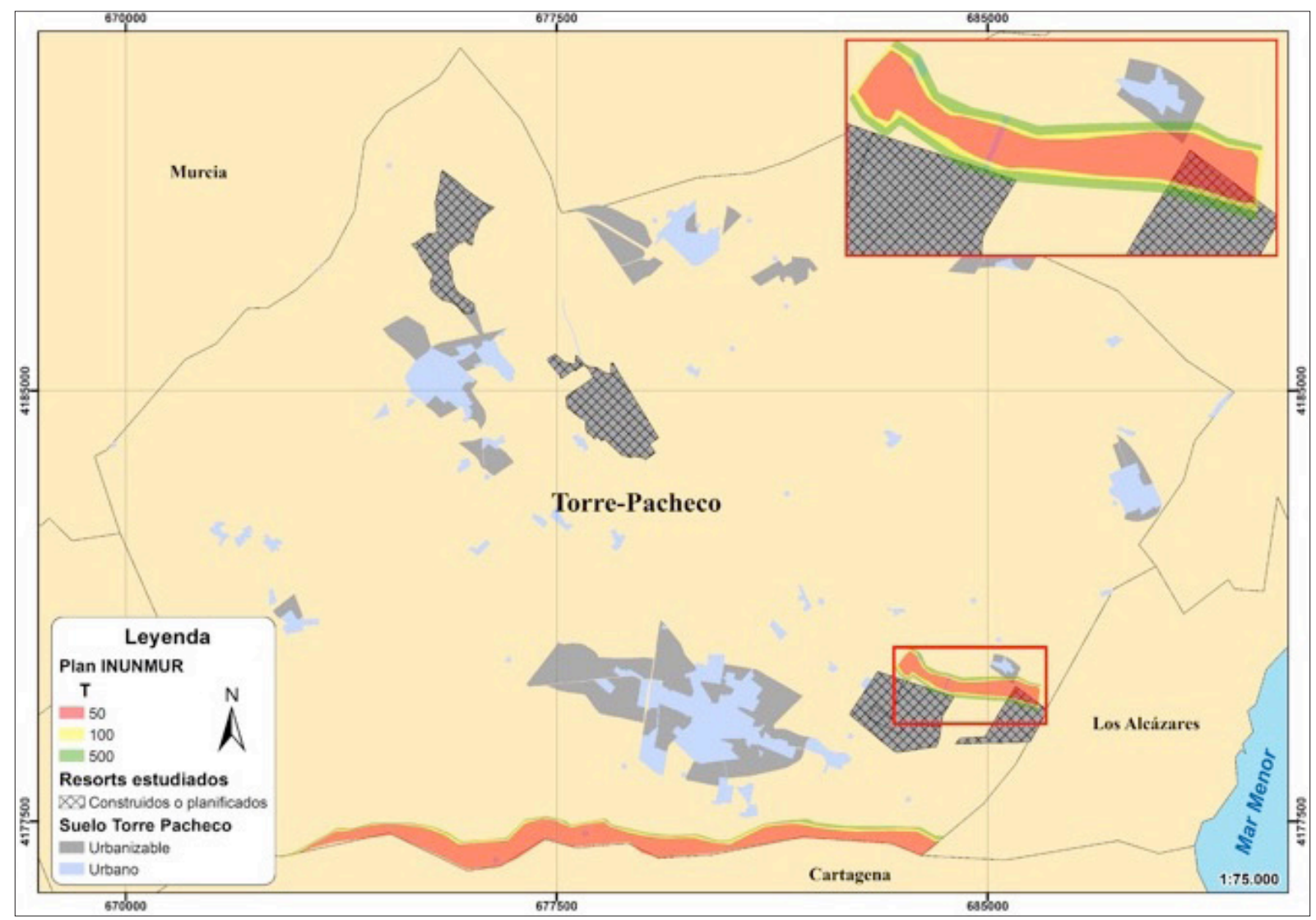

Figura 4: Cartografía del Plan INUNMUR y su posible al suelo urbano, urbanizable y resorts. Fuente: Elaboración propia.

\section{NNSS y SNCZI}

En este caso, al igual que ocurre con el Plan INUNMUR, como tanto las propias NNSS como sus posteriores modificaciones son bastante anteriores a la publicación del SNCZI, la consideración de este último es nula. No obstante, ante este escenario de riesgo e independientemente del $\mathrm{T}$ considerado, los resultados cambian drásticamente con respecto a los anteriores (cuadro 4).

\begin{tabular}{lccccc}
\hline $\mathbf{T}$ & $\begin{array}{c}\text { Superficie } \\
\text { inundable } \\
\text { (ha) }\end{array}$ & $\begin{array}{c}\text { Superficie } \\
\text { urbana } \\
\text { inundable (ha) }\end{array}$ & SUBI & $\begin{array}{c}\text { Superficie } \\
\text { urbanizable } \\
\text { inundable (ha) }\end{array}$ & SUZI \\
\hline $\mathbf{1 0}$ & $2.181,71$ & 26,94 & 2,10 & 144,27 & 11,23 \\
$\mathbf{5 0}$ & $3.530,22$ & 82,18 & 12,16 & 304,16 & 23,68 \\
$\mathbf{1 0 0}$ & $4.033,65$ & 105,63 & 15,62 & 378,47 & 29,47 \\
$\mathbf{5 0 0}$ & $4.913,47$ & 147,24 & 21,78 & 513,32 & 39,97 \\
\hline Promedio & $3.664,76$ & 90,50 & 12,92 & 335,06 & 26,09 \\
\hline
\end{tabular}

Cuadro 5: Superficie y porcentaje de las zonas inundables según el T.

Fuente: Elaboración propia. 
En primer lugar, destaca un aumento de la superficie inundable, circunstancia que revela una mejora sustancial en la precisión de los resultados cartográficos y la reducida utilidad que suponían los del Plan INNUMUR. De forma consecuente a la ampliación de la superficie inundable con esta acentuación de la superficie inundable, la SUBI sufre un notorio incremento hasta alcanzar un valor promedio de un 13\% (cuadro 5). Por otro lado, considerando la posible urbanización de toda la superficie actualmente destinada a tal fin, la SUZI alcanzaría un valor medio de $26,09 \%$, lo que equivale a duplicar con carácter general para los distintos T el valor de la SUBI.

\begin{tabular}{|c|c|c|c|c|}
\hline Resort & $\mathbf{T}$ & $\begin{array}{c}\text { Superficie } \\
\text { inundable (ha) }\end{array}$ & $\begin{array}{l}\text { Superficie } \\
\text { resort (ha) }\end{array}$ & $\begin{array}{r}\% \\
\text { inundable } \\
\end{array}$ \\
\hline Las Terrazas & 10 & 7,27 & 68,36 & 10,64 \\
\hline La Torre Golf Resort & 10 & 8,00 & 134,04 & 5,97 \\
\hline Mar Menor Golf Resort I & 10 & 0,77 & 89,23 & 0,86 \\
\hline Saurines La Torre Golf Resort & 10 & 47,55 & 155,37 & 30,61 \\
\hline Las Terrazas & 50 & 13,63 & 68,36 & 19,94 \\
\hline La Torre Golf Resort & 50 & 23,87 & 134,04 & 17,81 \\
\hline Mar Menor Golf Resort I & 50 & 5,27 & 89,23 & 5,91 \\
\hline Saurines La Torre Golf Resort & 50 & 76,98 & 155,37 & 49,54 \\
\hline Las Terrazas & 100 & 19,27 & 68,36 & 28,19 \\
\hline La Torre Golf Resort & 100 & 35,18 & 134,04 & 26,24 \\
\hline Mar Menor Golf Resort I & 100 & 9,89 & 89,23 & 11,09 \\
\hline Saurines La Torre Golf Resort & 100 & 82,91 & 155,37 & 53,36 \\
\hline Mar Menor Golf Resort II & 100 & 0,35 & 70,54 & 0,50 \\
\hline Las Terrazas & 500 & 33,37 & 68,36 & 48,82 \\
\hline La Torre Golf Resort & 500 & 62,89 & 134,04 & 46,92 \\
\hline Mar Menor Golf Resort I & 500 & 20,61 & 89,23 & 23,10 \\
\hline Saurines La Torre Golf Resort & 500 & 91,38 & 155,37 & 58,81 \\
\hline Mar Menor Golf Resort II & 500 & 1,40 & 70,54 & 1,98 \\
\hline
\end{tabular}

Cuadro 6: Datos básicos de cada resort y porcentaje de superficie en zona inundable.

Fuente: Elaboración propia.

Nuevamente, desglosando la superficie de los resorts fuera del planeamiento general, además de incrementarse el número de complejos afectados, también lo hace el área de cada uno (cuadro 6). En este sentido, deben destacarse los posibles daños ocasionados por las inundaciones en los complejos denominados como "Saurines 
La Torre Golf Resort" y "Las Terrazas", residenciales cuya superficie afectada por los eventos más recurrentes (T10) abarca un $30 \%$ y un 10\% de su superficie respectivamente (figura 6).

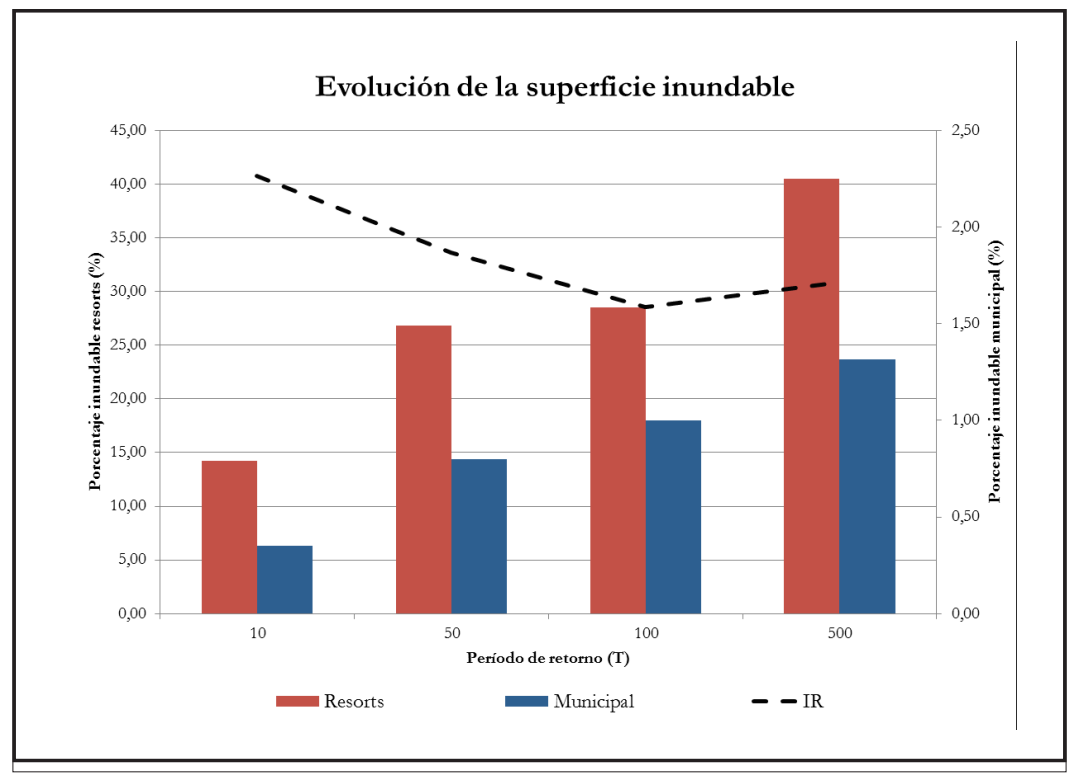

Figura 5: Gráfico con los porcentajes de superficie inundable registrada a nivel municipal y para los resorts.

Fuente: Elaboración propia.

Finalmente, respecto a la IR, a pesar del aumento generalizado de la superficie inundable tanto a nivel municipal como de resorts, su cuantía se reduce drásticamente para todos los T analizados hasta llegar a duplicar, en promedio, la superficie inundable de los resorts a la municipal (figura 5). Es decir, se confirma e incluso se acentúa lo señalado en el apartado anterior, los resorts están más expuestos a las inundaciones de mayor probabilidad que los núcleos de población tradicionales.

\section{Discusión y conclusiones}

La última fase de crecimiento urbano experimentada por los municipios del litoral superó sus límites tradicionales de primera línea de costa y alcanzó con fuerza a ámbitos de interior ${ }^{80}$. En la primera década del presente siglo, municipios de esta condición geográfica como el de Torre Pacheco, se sumaron a la dinámica desarrollista que hasta entonces se había ceñido a la costa de la forma más flagrante, es decir, habilitando de forma masiva nuevos espacios para la ubicación de un modelo de turismo asociado al residencialismo. La intencionalidad era clara, aprovechar unas condiciones de mercado inmobiliario óptimas a nivel internacional para mejorar una recaudación que elevó los ingresos en las arcas municipales hasta niveles nunca alcanzados ${ }^{81}$. Ni que decir tiene que a la vista del aciago balance obtenido en los resultados, las decisiones no fueron las más adecuadas y menos aún en lo que se refiere a la adaptación de dicho modelo a las condiciones físicas de cada municipio.

80 Aledo 2016; Mena, 2010

81 Inskeep, 1991 


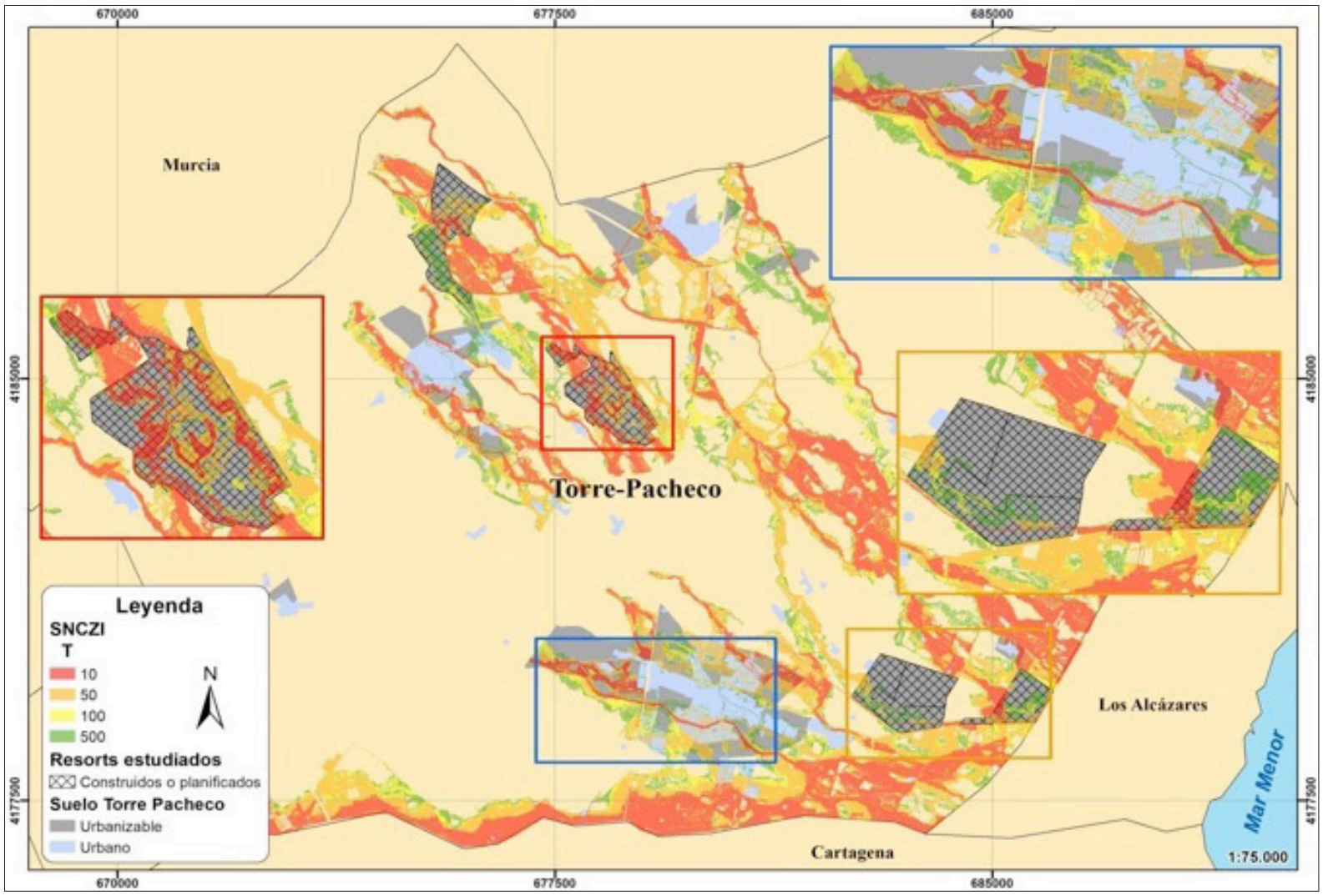

Figura 6: Cartografía del SNCZI y su posible al suelo urbano, urbanizable y resorts. Fuente: Elaboración propia.

A este respecto, durante la fase de redacción, posterior modificación y vigencia de las NNSS de Torre Pacheco, el papel de los planificadores locales destaca por su habilidad para aumentar la capacidad habitacional del término municipal, pero nada en absoluto para considerar debidamente el peligro de inundación por medio de la cartografía que se fue incorporando (Plan INUNMUR y SNCZI). Lo anterior, repetido con porfía por medio de diferentes fórmulas por todo el territorio español, se tradujo en un incremento desmedido de la superficie urbanizable en zonas inundables ${ }^{82}$ que las inundaciones recuerdan con una frecuencia creciente ${ }^{83}$.

A la vista de los resultados y los de otros autores ${ }^{84}$, llama la atención como esta situación cobra especial importancia en lo que se refiere a la ocupación de espacios inundables de alta probabilidad ( $\mathrm{T} 10$ ). En el presente caso, la superficie expuesta ha aumentado en aproximadamente un $450 \%$, algo que resulta poco explicable considerando las limitaciones de uso en dicha zona que establece la legislación de aguas española. Sin embargo se trata de un comportamiento corriente en un ámbito geográfico donde la red hidrográfica está compuesta por ramblas y barrancos que de forma natural permanecen secos durante largos periodos de tiempo, y tan solo ven interrumpida esta condición en situaciones transitorias tras lluvias de fuerte intensidad horaria. Todo lo anterior contribuye a una baja percepción del peligro

82 Pérez-Morales, 2015a; Acín Naverac et al., 2011; Olcina et al., 2010

83 Gil-Guirado et al., 2014

84 Jongman et al., 2014; Pérez-Morales et al., 2015a 
de inundación ${ }^{85}$ y, por extensión, a la ocupación de zonas inundables ${ }^{86}$. Otrora ese aprovechamiento se llevaba a cabo de forma sostenible por medio de actividades tradicionales ${ }^{87}$, sin embargo, desde mediados del siglo pasado, la presión demográfica y residencial desmantelaron cualquier relación de equilibrio y respeto con las zonas inundables, lo que hizo que se terminase por sucumbir a la tentación de ocupar aquellos cauces que permanecían continuamente secos. Esta forma de expansión urbana, experimentada sobre todo durante los boom inmobiliarios registrados en el litoral y en el área de estudio, evidencia un modelo de desarrollo galopante que obvia e, incluso, parece que hasta evita, cualquier medida de tipo adaptativa al medio físico sobre el que se asienta, sobre todo, después de los resultados cosechados en la comarca en la que se encuentra el municipio estudiado (ver problemas del Mar Menor, aeropuerto de Murcia, número de viviendas vacías, etc... $)^{88}$.

En lo que se refiere a la aportación específica del modelo resort al incremento de la superficie expuesta ante las inundaciones, los índices calculados para este fin, especialmente el IR, señalan que de media su superficie inundable duplica al resto la superficie urbana en zona inundable del municipio. Esta situación refleja claramente la importancia del componente social sobre la frecuencia y magnitud de las inundaciones, pues la transformación urbanística registrada en éste, así como en otros municipios españoles, ha aumentado tanto el número de propiedades expuestas en zonas inundables como su valor ${ }^{89}$. Los resultados obtenidos en el presente estudio coinciden con los que ya en su día apuntaban la Directiva Europea 2007/60/CE y el IPCC $^{90}$, que señalan al incremento de los asentamientos humanos y los bienes económicos expuestos en las llanuras aluviales como uno de los factores principales que han contribuido a elevar las probabilidades de inundaciones en el mundo, así como el balance de las pérdidas.

Por otro lado, este aumento inusitado de la superficie expuesta en los resort frente a la del suelo urbano y urbanizable cuestiona, una vez más, la falta de compromiso ético de los gestores territoriales municipales en el ejercicio de sus competencias. Obviamente, lo anterior no ha podido ser completamente demostrado salvo en casos flagrantes de corrupción ${ }^{91}$, sin embargo, un factor revelador sobre la facilidad y conveniencia que encontraron estos planificadores para ubicar los resort en zona inundable subyace en la falta de percepción generalizada. Por un lado, la de los mismos gestores, quienes además de no contar con la cartografía necesaria de precisión para delimitar las zonas inundables, obviaron los peligros derivados de las áreas circundantes de las pequeñas cuencas fluviales de comportamiento torrencial $^{92}$. Por otro lado, de los residentes, quienes ajenos tanto a las características

85 Llasat et al, 2008

86 Saurí et al., 2010

87 Morales, 1968

88 Pérez-Morales et al., 2017

89 Directiva 2007/60/EC; Jongman et al., 2014; Pérez-Morales et al., 2015a

90 IPCC, 2012; IPCC, 2014

91 Romero et al., 2012

92 Olcina, 2004 
climáticas como el comportamiento efímero de la red hidrográfica, adquirieron sus viviendas confiando en la seguridad de las mismas proporcionada por la administración ${ }^{93}$. En resumidas cuentas, el escenario comentado era el de un caldo de cultivo perfecto para el aumento sin control de la exposición.

Por último y en lo que se refiere a la cartografía analizada, se advierte una notoria evolución en la precisión y delimitación que requieren las zonas inundables. El SNCZI ha mejorado sustancialmente las carencias presentes en los mapas del Plan INUNMUR, convirtiéndose en una herramienta eficaz para reducir la vulnerabilidad institucional. Sin embargo, dos problemas dificultan su aplicación efectiva: en primer lugar, cualquier alteración de los cauces modelizados o de los procesos de sellado en la cuenca vertiente al mismo puede suponer una modificación de las zonas inundables ${ }^{94}$, máxime, cuando estos han sido transformados hasta la desfiguración, situación que exige una actualización prácticamente continúa ${ }^{95}$. En segundo, todavía existen problemas relacionados con los datos pluviométricos utilizados para el cálculo de los periodos de retorno y el posterior establecimiento de la peligrosidad de las inundaciones, puesto que la comparación entre los datos extremos calculados con datos empíricos reales raramente supera los 100 años por la falta de series largas. De manera que estas estimaciones pueden resultar científicamente criticables al basarse en la mera suposición de un comportamiento "mecánico" de la naturaleza, especialmente cuando el periodo de retorno asignado con este sistema supera el doble de la longitud temporal de la serie analizada ${ }^{96}$. Al respecto, Balasch ${ }^{97}$ et al. han calculado para la Cuenca del río Ebro una infraestimación de los periodos de retorno con respecto a la reconstrucción de caudales de inundaciones históricas de más del 25\%. En definitiva, pese al buen trabajo realizado en el SNCZI, es necesaria una mayor consideración de series empíricas más largas que permitan el ajuste correcto de esos máximos ${ }^{98}$. En este sentido, de aplicarse dicha metodología en el área de estudio es probable que la zona expuesta al peligro de inundaciones aumentara sus dimensiones.

\section{Bibliografía}

ACÍN NAVERAC, Vanesa, DÍAZ BEA, Elena, GRANADO GARCÍA, David, GONZÁLEZ DE MATAUCO, Askoa Ibisate, OLLERO OJEDA, Alfredo. Cambios recientes en el cauce y la llanura de inundación del área de confluencia Aragón-Arga (Navarra). Geographicalia, 2011, vol. 59-60, p.11-25.

ALEDO TUR, Antonio. De la tierra al suelo: la transformación del paisaje y el nuevo turismo residencial. Arbor, 2008, vol. 184(729), p. 99-113.

93 Figueiredo et al., 2009

94 Pérez-Morales et al., 2017

95 Olcina, 2012

96 Olcina, 2007

97 Balasch et al., 2014

98 Barriendos et al, 2014 
ALEDO TUR, Antonio, MAZÓN MARTÍNEZ, Tomás Manuel. Análisis y metodología para el estudio del sector turístico de una comarca: el caso del Bajo Segura (Alicante). Estudios turísticos, 1998, vol. 137, p. 55-66.

BARREDO, José. Major flood disasters in Europe: 1950-2005. Natural Hazards, 2007, vol. 42(1), p. 125-148.

BARRIENDOS, Manuel, RUIZ-BELLET, Josep Luis, TUSET, Jordi, MAZÓN, Jordi, BALASCH, Josep Carles, PINO, David, AYALA, Josep Luis. The" Prediflood" database of historical floods in Catalonia (NE Iberian Peninsula) AD 1035-2013, and its potential applications in flood analysis. Hydrology and Earth System Sciences, 2014, vol. 18(12), p. 4807-4823.

BALASCH, Josep Cares, MONSERRATE, Adrián, SÁNCHEZ, Alberto, ABELLÀ, Andreu, TUSET, Jordi, LLUÍS Josep, BARRIENDOS Mariano. Analysis of the major floods in the Ebro River basin (Iberian Peninsula) since 1600 AD. En EGU General Assembly Conference Abstracts, 2014, vol. 16, p. 5733.

CALVO GARCÍA-TORNEL, Francisco. Sociedades y Territorios en Riesgo. Barcelona: Ediciones Serbal, 2001, 180 p.

CALVO GARCÍA-TORNEL, Francisco. Algunas cuestiones sobre geografía de los riesgos. Scripta Nova, 1997, vol. 10.

CAMARASA-BELMONTE, Ana María. Crecidas e inundaciones. En AYALA-CARCEDO, Francisco Javier, OLCINA CANTOS, Jorge. Riesgos Naturales. Barcelona: Ariel, 2002, p. 859-879.

CAMARASA-BELMONTE, Ana María, SORIANO-GARCÍA, José. Flood risk assessment and mapping in peri-urban Mediterranean environments using hydrogeomorphology. Application to ephemeral streams in the Valencia region (eastern Spain). Landscape and Urban Planning, 2012, vol. 104(2), p. 189-200.

CARDONA, Omar Dario, VAN AALST, Marten Determinants of risk: exposure and vulnerability. In FIELD, Christopher et al. Managing the risks of extreme events and disasters to advance climate change adaptation. A special report of working groups I and II of the intergovernmental panel on climate change (IPCC). Cambridge University Press, 2012, p. 65-108.

COMISIÓN EUROPEA. Directiva 2007/60/EC del Parlamento y el Consejo Europeo sobre evaluación y gestión de los riesgos de inundación. Bruselas: Consejo de Europa, 2007, 7 p.

CREM. Centro Regional de Estadística de Murcia. Datos municipales [en línea]: <http://econet.carm.es/> [Consulta: 25 Septiembre 2016].

DÍAZ ORUETA, Fernando. Turismo, urbanización y cambio social. Revista Argentina de Sociología, 2004, vol. 2, p. $115-127$.

FIGUEIREDO, Elisabete, VALENTE, Sandra, COELHO, Celeste, PINHO, Luísa. Coping with risk: analysis on the importance of integrating social perceptions on flood risk into management mechanisms - the case of the municipality of Agueda, Portugal. Journal of Risk Research, 2009, vol. 12(5), p. 581-602. 
FERNÁNDEZ MUÑOZ, Santiago. La ausencia de referentes internacionales en el desarrollo del litoral español. Estudios Turísticos, 2007, vol. 172-173, p. 83-88.

FERNÁNDEZ MUÑOZ, Santiago, BARRADO TIMÓN, Diego. El desarrollo turístico-inmobiliario de la España Mediterránea e Insular frente a sus referentes internacionales (Florida y la Costa Azul): Un análisis comparado. Cuadernos de Turismo, 2011, vol. 27, p. 373-402.

FUENTES ZORITA, José Luis, CALVO GARCÍA-TORNEL, Francisco. Estudio-propuesta de comarcalización de la región de Murcia. Estudios de delimitación comarcal de la región de Murcia. Consejería de Política Territorial y Obras públicas. Comunidad Autónoma de Murcia, 1984, 18 pp.

FUCHS, Sven. Susceptibility versus resilience to mountain hazards in Austria - paradigms of vulnerability revisited. Natural Hazards and Earth System Sciences, 2009, vol. 9, p. 337-352.

FUCHS, Sven, RÖTHLISBERGER, Veronika, THALER, Thomas, ZISCHG, Andreas, KEILER, Margreth. Natural hazard management from a co-evolutionary perspective: exposure and policy response in the European Alps. Annals of the American Association of Geographers, 2017, vol. 107(2), p. 382-392.

GIDDENS, Anthony. Modernidade e identidade. Río de Janerio: Jorge Zahar, 2002, 233 pp.

GIL-GUIRADO, Salvador, PÉREZ-MORALES, Alfredo, BARRIENDOS, Mariano. Increasing vulnerability to flooding in the southern spanish mediterranean coast (1960-2013). En Hydrological extreme events in historic and prehistoric times, 2014. Universidad de Bonn.

GONZÁLEZ REVERTÉ, Francesc. El papel de los destinos turísticos en la transformación sociodemográfica del litoral mediterráneo español. Boletín de la Asociación de Geógrafos Españoles, 2008, vol.47, p. 79-102.

GRENON, Michel, BATISSE, Michel. El plan azul: el futuro de la Cuenca Mediterránea. Madrid: Ministerio de Obras Públicas y Transporte, 1990, 500 pp.

HOOKE, Jannet. Human impacts on fluvial systems in the Mediterranean region. Geomorphology, 2006, vol. 79(3), p. 311-335.

HOLUB, Markus, FUCHS, Sven. Mitigating mountain hazards in Austria - Legislation, risk transfer, and awareness building. Natural Hazards and Earth System Sciences, 2009, vol. 9(2), p. 523-537.

INSKEEP, Edward. Tourism planning: an integrated and sustainable development approach. London: Van Nostrand Reinhold, 1991, 528 p.

INE. Instituto Nacional de Estadística. Padrón. Población por municipios [en línea]: <http://www.ine.es/> [Consulta: 18 Julio 2016].

INSTITUTO DE TURISMO DE ESPAÑA. Ministerio de Industria, Energía y Turismo [en línea]: <http://www.tourspain.es/es-es/Paginas/index.aspx> [Consulta: 20 Septiembre 2016]. 
IPPC. Managing the risks of extreme events and disasters to advance climate change adaptation: special report of the intergovernmental panel on climate change. Intergovernmental Panel on Climate Change - IPPC, Cambridge University Press, 2012, $594 \mathrm{pp}$.

IPPC. Synthesis Report. Contribution of Working Groups I, II and III to the Fifth Assessment Report of the Intergovernmental Panel on Climate Change. Intergovernmental Panel on Climate Change - IPPC, 2014, Geneva, Switzerland, 151 pp. LANE, Stuart, LANDSTRÖM, Catharina, WHATMORE, Sarah. Imagining flood futures: risk assessment and management in practice. Philosophical Transactions of the Royal Society A, 2011, vol. 369, p. 1784-1806.

LLASAT, Maria del Carmen, LÓPEZ, Laura, BARNOLAS, Manuel, LLASAT-BOTIJA, Maria del Carmen. Flash-floods in Catalonia: the social perception in a context of changing vulnerability. Advances in Geosciences, 2008, vol. 17, p. 63-70.

LLASAT, Maria del Carmen, LLASAT-BOTIJA, Mari del Carmen, PRAT, Miguel Ángel, PORCÚ, Federico, PRICE, Colin, MUGNAI, Alberto, LAGOUVARDOS, Kostas, KOTRONI, Vassiliki, KATSANOS, Dimitros, MICHAELIDES, Silas, YAIR, Yoav, SAVVIDOU, Keti, NICOLAIDES, Kleanthis. High-impact floods and flash floods in Mediterranean countries: the FLASH preliminary database. Advances in Geosciencies, 2010, vol. 23, p. 47-55.

MANTECÓN, Alejandro, HUETE, Raquel, MAZÓN, Tomás. Las urbanizaciones “europeas". Una investigación sobre las nuevas sociedades duales en el Mediterráneo. Scripta Nova, 2009, vol. 13.

MAZÓN, Tomás. El turismo litoral mediterráneo: ¿políticas turísticas o desarrollo inmobiliario. In RODRIGUEZ, Josep. Sociología para el futuro. Barcelona: Icaria, 2006, p. 301-310.

MAZÓN, Tomás. Inquiring into residential tourism: The Costa Blanca case. Tourism and Hospitality Planning \& Development, 2006, vol. 3(2), p. 89-97.

MAZÓN, Tomás, ALEDO TUR, Antonio. El dilema del turismo residencial: ¿ turismo o desarrollo inmobiliario?. En MAZÓN, Tomás, ALEDO TUR, Antonio. Turismo residencial y cambio social: nuevas perspectivas teóricas y empíricas. Universidad de Alicante, 2005, p. 13-30.

MINISTERIO DE HACIENDA Y ADMINISTRACIONES PÚBLICAS. Dirección General del Catastro [en línea]: <http://www.sedecatastro.gob.es/> [Consulta: 20 Agosto 2016].

MENA HORNILLOS, Javier. El modelo urbanizador resort: análisis, contexto y repercusiones en el campo de Murcia y el Mar Menor. Director: Francisco Segado Vázquez. Tesis Doctoral, 2010. Universidad Politécnica de Cartagena, Cartagena, p. 360.

MINISTERIO DE AGRICULTURA, ALIMENTACIÓN Y MEDIO AMBIENTE. Sistema Nacional de Cartografía de Zonas Inundables. [en línea]: <http://www.mapama. gob.es/es/agua/temas/gestion-de-los-riesgos-de-inundacion/snczi/> [Consulta: 10 Julio 2016]. 
MOEL, Hans, ALPHEN, Jan Van, AERTS, Jeroen. Flood maps in Europe-methods, availability and use. Natural Hazards and Earth System Sciences, 2009, vol. 9(2), p. 289-301.

MORALES GIL, Alfredo. El riego con aguas de avenida en las laderas subáridas. Papeles de Geografía, 1968, vol. 1, p. 167-187.

NEUVEL, Jeroen, VAN DEN BRINK, Adri. Flood risk management in Dutch local spatial planning practices. Journal of Environmental Planning and Management, 2009, vol. 52(7), p. 865-880.

OLCINA CANTOS, Jorge. Riesgos de inundaciones y ordenación del territorio en la escala local. El papel del planeamiento urbano municipal. Boletín de la Asociación de Geógrafos Españoles, 2004, vol. 37, p. 49-84.

OLCINA CANTOS Jorge. Riesgo de inundaciones y ordenación del territorio en España. La consideración del peligro de inundaciones en los procesos de planificación territorial. Alicante, Fundación Instituto Euromediterráneo del Agua, 2007, $220 \mathrm{pp}$.

OLCINA CANTOS, Jorge. El tratamiento de los riesgos naturales en la planificación territorial de escala regional. Papeles de Geografía, 2010, vol. 51-52, p. 223-234.

OLCINA CANTOS, Jorge. De los mapas de zonas afectadas a las cartografías de riesgo de inundación en España. Anales de geografía de la Universidad Complutense, 2012, vol. 32, p. 91-131.

OLCINA CANTOS, Jorge, HERNÁNDEZ HERNÁNDEZ, María, RICO AMORÓS, Antonio, MARTÍNEZ IBARRA, Emilio. Increased risk of flooding on the coast of Alicante (Region of Valencia, Spain). Natural Hazards and Earth System Sciences, 2010, vol. 10, p. 2229-2234.

PAPATHEODOROU, Andreas. Exploring the evolution of tourism resorts. Annals of Tourism Research, 2004, vol. 31(1), p. 219-237.

PARKER, Dennis, TAPSELL, Sue. Deliverable 2.1. Relations between different types of social and economic vulnerability. European Commission: ENSURE Project, 2009, $50 \mathrm{p}$.

PÉREZ-MORALES, Alfredo. La valoración del riesgo de inundación en los instrumentos de gobernanzas municipales del sur de Murcia. Investigaciones Geográficas, 2009, vol. 48, p. 97-123.

PÉREZ-MORALES, Alfredo. Estado actual de la cartografía de los riesgos de inundación y su aplicación en la ordenación del territorio. El caso de la Región de Murcia. Boletín de la Asociación de Geógrafos Españoles, 2012, vol. 58, p. 57-82. PÉREZ-MORALES, Alfredo, GIL-GUIRADO, Salvador, OLCINA CANTOS, Jorge. Housing bubbles and increase of the exposure to floods. Failures in the floods management in the Spanish coast. Journal of Flood Risk Management, $2015 \mathrm{a}$.

PÉREZ-MORALES, Alfredo, GIL-GUIRADO, Salvador, MARTÍN, Fernando. Veinte años de protección de cauces en el litoral de la Región de Murcia (1994-2014). Evaluación de la eficiencia de las medidas de Ordenación del Territorio. Anales de geografía de la Universidad Complutense, 2015b, vol. 35, p. 169-185. 
PÉREZ-MORALES, Alfredo, ROMERO DÍAZ, Asunción, CABALLERO PEDRAZA, Agustín. Procesos de urbanización y su influencia en el incremento de inundaciones (Sureste de España, Región de Murcia, Campo de Cartagena-Mar Menor). Aportación del Comité Español de la Unión Geográfica International. The 33th International Geographical Congress. IGU, Beijing, 2017, p. 97-113.

ROMERO, Juan, JIMÉNEZ, Fernando, VILLORIA, Manuel. (Un) sustainable territories: causes of the speculative bubble in Spain (1996-2010) and its territorial, environmental, and sociopolitical consequences. Environment and planning C: Government and policy, 2012, vol. 30(3), p. 467-486.

ROMERO DÍAZ, Asunción, MAURANDI GUIRADO, Antonio. Las inundaciones en la cuenca del Segura en las dos últimas décadas del siglo XX: actuaciones de prevención. Serie Geográfica, 2000, vol. 9, p. 93-120.

ROMERO DÍAZ, Asunción, CABALLERO PEDRAZA, Agustín, PÉREZ-MORALES, Alfredo. Expansión urbana y turismo en la Comarca del Campo de Cartagena-Mar Menor (Murcia). Impacto en el sellado del suelo. Cuadernos de Turismo, 2017, vol. 39, pp. 521-546.

SAURÍ, David, RIVAS, Anna, LARA, Alejandro, PAVÓN, David. La percepción del riesgo de inundación: experiencias de aprendizaje en la Costa Brava. Papeles de Geografía, 2010, vol. 51-52, p. 269-278.

SISTEMA DE INFORMACIÓN TERRITORIAL DE LA REGIÓN DE MURCIA. Planeamiento urbanístico municipal [en línea]: < http://sitmurcia.carm.es/> [Consulta: 12 Julio 2016].

SMITH, Keith, PETLEY, David. Environmental Hazards: Assessing Risk and Reducing Disaster. London: Routledge Editorial, 2009, 422 p.

SQUIRES, Gregory. Urban sprawl and the uneven development of metropolitan America. IN SQUIRES, Gregory. Urban Sprawl: Causes, Consequences, and Policy Responses. Whasinghton: Urban Institute Press, 2002, p. 1-22.

SUTANTA, Heri, RAJABIFARD, Abbas, BISHOP, Ian. Integrating spatial planning and disaster risk reduction at the local level in the context of spatially enabled government. En RAJABIFARD, Abbas, CROMPVOETS, Joep, MOHSEN, Kalantari, BAS, Kok. Spatially Enabling Society, Research, Emerging Trends and Critical Assessment. Leuven: Leuven University Press, 2010, p. 205-218.

WISNER, Benjamin. From “'Acts of God “ to “'Water Wars” - The urgent analytical and policy role of political ecology in mitigating losses from flood: A view of South Africa from Central America. En Parker, Dennis. Floods. London: Routlege, 2000, p. 88-99.

WISNER, Benjamin, BLAIKIE, Piers, CANNON, Terry, Davis, Ian. At risk: natural hazards, people's vulnerability, and disasters. London: Routledge, 2004, 134 pp.

WILCHES-CHAUX, G. La vulnerabilidad global. En Maskrey, Andrew. Los desastres no son naturales. LA RED, 1993, p. 9-50. 
(c) Copyright: Francisco López Martínez y Alfredo Pérez Morales, 2017

(c) Copyright Scripta Nova, 2017.

Ficha bibliográfica:

LÓPEZ MARTÍNEZ, Francisco; PÉREZ MORALES, Alfredo. Influencia del turismo residencial sobre el riesgo de inundación en el litoral de la Región de Murcia. Scripta Nova. Revista Electrónica de Geografía y Ciencias Sociales. [En línea]. Barcelona: Universidad de Barcelona, 1 de noviembre de 2017, vol. XXI, nº 577. ISSN: 1138-9788. 
